MARISTELA GOMES DE ALMEIDA

\title{
Estudo da microbiota intestinal em doentes com retocolite ulcerativa antes e após retocolectomia com anastomose de bolsa ileal ao canal anal
}

Tese apresentada à Faculdade de Medicina da Universidade de São Paulo para obtenção do título de Doutor em Ciências.

Área de Concentração: Cirurgia do Aparelho Digestivo

Orientador: Prof. Dr. Desidério Roberto Kiss

Co-orientador: Prof. Dr. Bruno Zilberstein

SÃO PAULO

2003 
ALMEIDA, M. G. Estudo da microbiota intestinal em doentes com retocolite ulcerativa antes e após retocolectomia com anastomose de bolsa ileal ao canal anal. São Paulo, 2003. 98p. Tese (Doutorado) - Faculdade de Medicina, Universidade de São Paulo.

A retocolite ulcerativa (RCU) é uma doença de etiologia desconhecida, onde a possivel associação de fatores genéticos, ambientais e alterações da microbiota intestinal, poderia atuar sobre a resposta imune intestinal, desencadeando o processo inflamatório característico desta doença. O objetivo deste estudo foi identificar a microbiota do muco intestinal de pacientes portadores de RCU grave, antes e após realização de retocolectomia com anastomose de bolsa ileal ao canal anal, comparando-a com a microbiota de um grupo controle. Trata-se de estudo prospectivo, com 10 pacientes portadores de RCU grave. Seis eram do sexo masculino e quatro do feminino, com média de idade de 38,5 anos. Após preparo intestinal anterógrado com manitol a 10\%, finalizado cinco horas antes do exame, o muco foi colhido no íleo terminal, ceco, ascendente, transverso, descendente, sigmóide e reto, através de sondas estéreis, com extremidade distal encapada com película de microfilme. As 
amostras foram enviadas ao laboratório de microbiologia num prazo máximo de 60 minutos, para semeio e cultura em meios seletivos para anaeróbios e aeróbios. No pós-operatório, realizou-se coleta única de muco na bolsa ileal. A concentração microbiana foi expressa em base logaritmica de $10\left(\log _{10}\right)$ das unidades formadoras de colônias (ufc) por mililitro (ml), nas razões decimais seriadas de $10^{1} \mathrm{a}$ 1010. Formaram-se três grupos de estudo: Grupo I - Microbiota dos doentes com RCU; Grupo II - Microbiota da bolsa ileal, dois meses (fase-1) e oito meses (fase-2) após o fechamento da ileostomia; Grupo III - Microbiota intestinal de indivíduos normais, de estudo realizado por QUINTANILHA et al. (2001). Para melhor compreensão dos dados obtidos, comparou-se a microbiota do íleo terminal e reto do Grupo I, com a microbiota do Grupo II e com o íleo terminal e o reto Grupo III. No Grupo I, foram isoladas 25 bactérias, com média de 16,7 por segmento. No íleo terminal e no reto deste grupo, as mais freqüentes foram a Veillonella sp (80\% e $70 \%)$ e o Enterobacter sp (60\% e $70 \%)$. As maiores concentrações médias foram da Escherichia coli (5.50) no íleo terminal e Proteus sp (7.00) e Bacteroides sp não pigmentado (6.00) no reto. No Grupo II (fase-1), foram isoladas 16 bactérias, com média de 7,2 por paciente, sendo as mais freqüentes: Veillonella $s p$ (90\%), Enterobacter sp (70\%), Klebsiella $s p(70 \%)$ e Staphylococcus $s p$ (70\%). Na fase-2 deste grupo também foram isoladas 16 bactérias, sendo as mais freqüentes a Veillonella $s p(50 \%)$ e a Escherichia coli (50\%). Comparando-se os Grupos I e III, observou-se que a Klebsiella 
$s p$ foi significativamente mais freqüente no íleo do Grupo III e Escherichia coli, Lactobacillus sp, Enterococcus sp e Klebsiella sp, no reto deste grupo. Na comparação das concentrações médias, Clostridium sp (gel-), Klebsiella $s p$ e Propionibacterium $s p$ são significativamente superiores no íleo terminal do grupo III, enquanto Escherichia coli, Enterococcus sp, Klebsiella $s p$ e Lactobacillus $s p$ são superiores no reto. Entre os Grupos II (fase-1) e III, observou-se que na comparação com o îleo terminal, a bactéria Enterobacter $s p$ foi significativamente mais freqüente no Grupo II, enquanto Enterococcus $s p$ e Fusobacterium foram mais freqüentes no reto do Grupo III. As concentrações médias do Enterobacter sp e Sthaphylococcus sp (coag-) foram significativamente mais elevadas no Grupo II, quando comparado com o íleo terminal, enquanto que Bacteróides sp (npg), Lactobacillus $s p$ e Veillonella $s p$ foram superiores no reto. Comparando-se o íleo terminal e o reto do Grupo I com o Grupo II (fase-1 e fase-2), observou-se que a freqüência e a concentração média da Klebsiella $s p$ foi significativamente maior na fase-1 do Grupo II, quando comparado com o íleo terminal. Conclui-se que, no presente estudo, a Veillonella $s p$ foi a bactéria mais freqüentemente encontrada em todos os grupos e que, mesmo apresentando algumas variações, a microbiota do muco intestinal não sofre alterações significativas nos pacientes com retocolite ulcerativa. 


\section{ALMEIDA, M. G. Intestinal microbiota in patients with ulcerative colitis before and after proctocolectomy and ileal pouch- anal anastomosis. São Paulo, 2003. 98p. Tese (Doutorado) - Faculdade de Medicina, Universidade de São Paulo.}

Ulcerative colitis (UC) is a disease of unknown etiology. The hypothetical association of genetic and environmental factors, and changes in the intestinal microbiota could act in the intestinal immunologic response, raising the characteristic inflammatory process of this disease. The aim of this study was to identify the microbiota of intestinal mucus in patients with severe ulcerative colitis, before and after proctocolectomy with ileal pouch-anal anastomosis, and compare to the microbiota of controls. This was a prospective study, consisting of 10 patients with severe ulcerative colitis. Six were male and four were female, the mean age was 38.5 years. Intestinal mucus was collected before and after proctocolectomy with ileal pouch-anal anastomosis. After intestinal mechanical oral prepare, with a 10\% mannitol solution five hours before the exam, mucus collection was performed at distal ileum, cecum, ascending, transverse and descending bowel, sigmoid and rectum, utilizing a sterile probe with the distal extremity covered by a plastic microfilm. Samples were send to the microbiology laboratory at least 60 minutes after collection, to sow and to culture in selective media for aerobic and anaerobic. After surgery, a single mucus collection of the ileal pouch was performed for each patient. Bacteria 
concentration was expressed in a logarithmic rate of $10\left(\log _{10}\right)$ of the colony-forming units ( $\mathrm{CFU}$ ) per milliliter $(\mathrm{ml})$, in a serial decimal rate of $10^{1}$ to $10^{10}$. Three different study groups were formed: group I microbiota of UC patients; group II - microbiota of the ileal pouch, two months (phase 1) and eight months (phase 2) after ileostomy closure; group III - intestinal microbiota of healthy patients, as observed in a study of QUINTANILHA et al. (2001). In order to a better understanding of the collected data, the microbiota of distal ileum and rectum in group I, was compared to the microbiota of group II and to the distal ileum and rectum microbiota of group III. In group I, 25 bacteria were isolated, mean of 16.7 per segment. At the distal ileum and rectum of this group, the most frequently found were Veillonella $s p(80 \%$ and $70 \%)$ and Enterobacter sp (60\% and $70 \%)$. The highest mean concentration found was of Escherichia coli (5.50) at the distal ileum and Proteus $s p$ (7.00) and Bacteroides $s p$ nonpigmented (6.00) at the rectum. In group II (phase 1) 16 bacteria were isolated, mean of 7.2 per patient. The most frequent were: Veillonella sp (90\%), Enterobacter sp (70\%), Klebsiella sp (70\%) and Staphylococcus $s p(70 \%)$. At phase 2 of this group, 16 bacteria were also isolated, Veillonella sp (50\%) and Escherichia coli (50\%) being the most frequent. Comparing group I and III, it was observed that Klebsiella $s p$ was significantly more frequent at the ileum in group III and Escherichia coli, Lactobacillus sp, Enterococcus sp and Klebsiella $s p$, at the rectum of that group. Comparing the mean concentrations, Clostridium $s p$ (gel-), Klebsiella $s p$ and Propionibacterium $s p$ were significantly higher at the terminal ileum of group III, while Escherichia coli, Enterococcus sp, Klebsiella $s p$ and Lactobacillus $s p$ were higher at the rectum. Regarding group II (phase 1) and III, it was noted that in relation to the distal ileum, the bacterium Enterobacter $s p$ was significantly more frequent in group II, while Enterococcus $s p$ and Fusobacterium were more frequent at the rectum in group III. The mean concentration of Enterobacter $s p$ and Staphylococcus sp (coag-) 
were significantly higher in group II, when compared to the distal ileum, while Bacteroides $s p$ (npg), Lactobacillus $s p$ and Veillonella $s p$ were higher at the rectum. Comparing the distal ileum and the rectum in group I with group II (phase 1 and phase 2), Klebsiella $s p$ was significantly higher in group II (phase 1), in frequency and mean concentration, when compared with distal ileum. In conclusion, at the present study, Veillonella $s p$ was the most frequent bacterium found in all studied groups, moreover, even with some variations, the microbiota of the intestinal mucus does not show significant changes in patients with ulcerative colitis. 
Lista de abreviaturas

Lista de tabelas

Lista de gráficos

Resumo

Summary

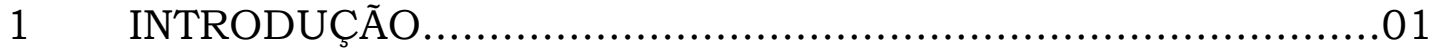

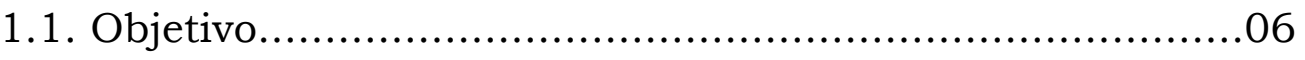

2 REVISÃO DA LITERATURA............................................

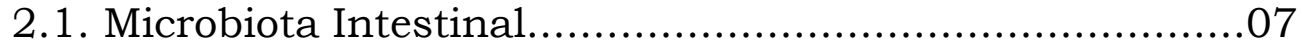

2.2. Funções relacionadas com a microbiota intestinal...........13

2.3. Fatores bacterianos nas doenças inflamatórias

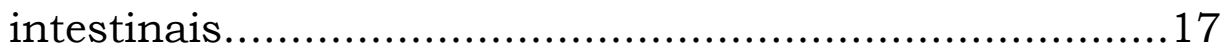

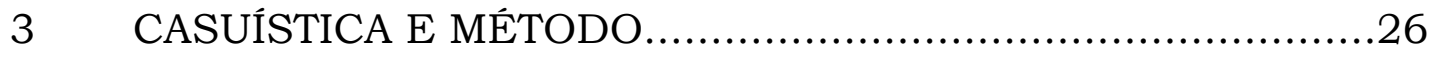

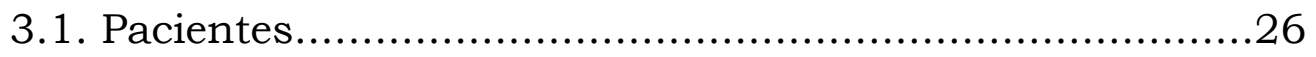

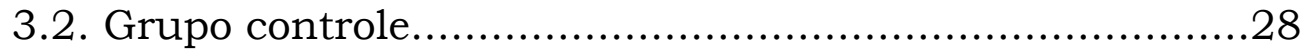

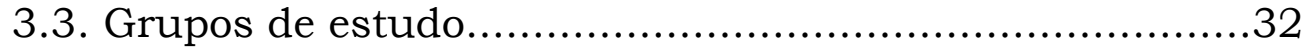

3.4. Videocolonoscopia e coleta do material...........................33

3.5. Semeadura e cultura das amostras coletadas.................35

3.6. Comparações entre os grupos estudados........................37

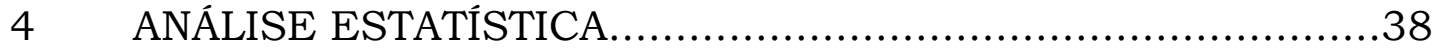


5.1. Grupo I -Microbiota dos pacientes com RCU................30

5.2. Comparação entre os grupos I e III - ileo terminal.........44

5.3. Comparação entre os grupos I e III - reto....................51

5.4. Grupo II - Bolsa ileal- primeira coleta (bolsa ileal-fase 1)..56

5.5. Comparação entre o grupo II (fase 1) e o grupo III (îleo terminal).

5.6. Comparação entre o grupo II (fase 1) e o reto do grupo III.61

5.7. Grupo II - Bolsa ileal- segunda coleta ( bolsa ileal-fase2).65

5.8. Comparação entre íleo terminal e reto do Grupo I (RCU) e as fases 1 e 2 do Grupo II....................................66

5.9. Resumo das comparações de freqüências....................70

5.10. Resumo das comparações das concentrações.............71

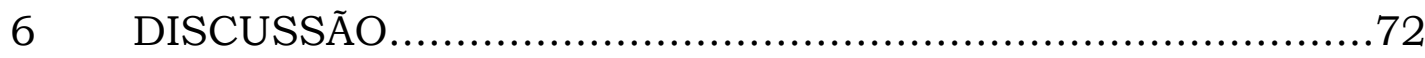

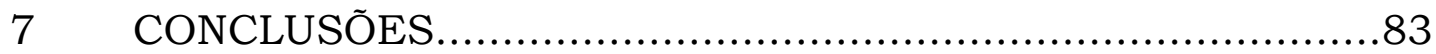

8 REFERÊNCIAS BIBLIOGRÁFICAS...............................84 APENNDICE 
$\alpha$-hem - alfa hemolítico

(coag-) - coagulase negativo(a)

$($ coag +$)-$ coagulase positivo(a)

DII - doença inflamatória intestinal

E. coli - Escherichia coli

et al. - e outros

g - grama

(gel-) - gelatina negativa

(gel+) - gelatina positiva

$\log$ - logaritmo

$\mathrm{ml}$ - mililitro

npg - não pigmentado

PCR - reação em cadeia da polimerase

pg - pigmentado

RCU - retocolite ulcerativa

RNA - ácido ribonucleico

ufc - unidades formadoras de colônias 
TABELA 1 - Medicação em uso durante coleta do material.

28

TABELA 2 - Concentração média $\left(\log ^{10}\right)$ das bactérias no íleo terminal - grupo controle. 30

TABELA 3 - Concentração média $\left(\log ^{10}\right)$ das bactérias no reto-grupo controle.

TABELA 4- Concentração média $\left(\log ^{10}\right)$ das bactérias mais freqüentes por segmento, nos pacientes do grupo I. .43

TABELA 5 - Frequência das bactérias (concentração superior a $10^{1}$ ) no íleo terminal dos grupos I e III.

TABELA 6 -Concentração das bactérias $\left(\log ^{10}\right)$ no íleo terminal dos grupos I e III 49-50

TABELA 7- Freqüência das bactérias no reto - grupo III (controle) X grupo I (RCU).

TABELA 8 - Concentração das bactérias $\left(\log ^{10}\right)$ no reto dos grupos I e III. $.54-55$

TABELA 9- Concentração bacteriana e freqüência das bactérias no grupo II-fase 1 56

TABELA 10 - Frequência das bactérias - comparação entre íleo do grupo III (controle) e o grupo II (fase 1).... 
TABELA 11 - Concentração das bactérias $\left(\log ^{10}\right)$ nos grupos II (fase-1) e III (illeo terminal). $59-60$

TABELA 12 - Frequência das bactérias - reto do grupo controle $\mathrm{X}$

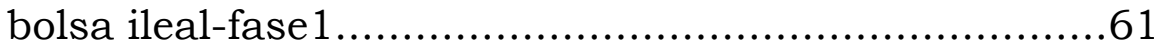

TABELA 13 - Comparação das concentrações bacterianas nos grupos II fase 1) e III (reto) 63-64

TABELA 14- Bactérias da bolsa ileal -fase 2 .65

TABELA 15 - Frequência das bactérias antes e após bolsa ileal.......67

TABELA 16 - Concentração da Klebsiella sp ao longo das fases.......68

TABELA 17- Log da concentração do Staphylococcus sp (cog -) ao

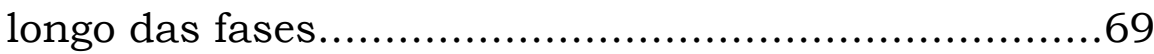


GRÁFICO 1- Freqüência das bactérias no íleo terminal do Grupo I (RCU) e Grupo III (controle). 45

GRÁFICO 2- Box-plot da concentração média do Clostridium sp......47

GRÁFICO 3- Box-plot da concentração média da Klebsiella sp.......47

GRÁFICO 4- Box-plot da concentração da Propionibacterium sp.......48

GRÁFICO 5- Box-plot da concentração da Veillonella sp............48

GRÁFICO 6- Freqüência das bactérias no reto..........53

GRÁFICO 7- Freqüência das bactérias.....58

GRÁFICO 8- Freqüência das bactérias..............62

GRÁFICO 9- Concentração da Klebsiella sp ao longo das fases.....68

GRÁFICO 10- Concentração do Staphylococcus sp (coag-) ao longo das fases....................................................69 
Marco Pólo: O inferno dos vivos não é algo que será; se existe, é aquele que já está aqui, o inferno no qual vivemos todos os dias, que formamos estando juntos. Existem duas maneiras de não sofrer. $A$ primeira é mais fácil para a maioria das pessoas: aceitar o inferno e tornar-se parte deste até o ponto de deixar de percebê-lo. A segunda é arriscada e exige atenção e aprendizagem contínuas: tentar saber reconbecer quem e o que, no meio do inferno, não é inferno, e preservá-lo, e abrir espaço.

\section{(Ítalo Calvino - As Cidades Invisíveis)}




\section{Meu sincero e emocionado agradecimento:}

Ao orientador e amigo, Prof. Dr. Desidério Roberto Kiss, pelo seu dom de permitir o crescimento profissional e espiritual dos que o cercam, pelo acolhimento entusiasmado dos meus projetos e pelas lições de vida das horas compartilhadas.

Ao Prof. Dr. Bruno Zilberstein, que na convivência pela co-orientação desta tese, mostrou ser um verdadeiro mestre, encorajando-me, com seu brilhantismo intelectual, a ver as qualidades e não apenas os defeitos.

À Profa. Dra. Angelita Habr-Gama, por tudo que representa na especialidade, mas principalmente pela força de vida que a torna ímpar.

Ao Prof. Dr. Joaquim Gama-Rodrigues, pela oportunidade e estimulo constantes, que muito me ajudaram a superar os desafios.

À Profa. Dra. Magaly Gêmio Teixeira, a quem admiro e respeito pela seriedade que norteia suas atitudes, pela dedicação a tudo que se propõe a fazer e pela amizade que muito estimo.

Ao Dr. Sylvio Figueiredo Bocchini, literalmente meu primeiro mestre em São Paulo, pela vibração sincera e pelos ensinamentos nunca esquecidos.

Ao Prof. Manoel Armando Azevedo dos Santos, pela realização de toda bacteriologia deste estudo, pelo rigor de seus resultados e pela paciência que sempre demonstrou.

À Dra. Alina Quintanilha, pelo apoio irrestrito na elaboração da metodologia e da coleta do material, pelo entusiasmo que contagia, pela vontade de ajudar.

A todos os membros da Disciplina de Coloproctologia do Departamento de Gastroenterologia do Hospital das Clínicas da Universidade de São Paulo, pelo apoio e convivência agradável que muito me honram.

Ao Serviço de Coloproctologia do Hospital do Servidor Público Municipal de São Paulo, em especial a seu chefe, Dr José Antônio Volpiani, pelo apoio irrestrito e estimulo profissional constante, pelas atitudes de amizade. 
Ao Dr. Antonio Carlos Baraviera, pelo companheirismo de todos os anos que trabalhamos juntos, dividindo tarefas e tornando mais fácil esta caminhada.

Às secretárias da pós-graduação, Mirtes, Sandra Regina, Vilma e Fabiana, pelo apoio indispensável e por simplicar tarefas sem perder a alegria.

À Sra. Mitti Ayako Hara Koyama, do Instituto de Matemática e Estatística da Universidade de São Paulo, pela seriedade e paciência na realização do estudo estatístico.

À Sra. Sônia, da biblioteca da FMUSP, pela simpatia e realização da ficha catalográfica.

Às funcionárias do ambulatório e da colonoscopia, Neusa e Maria, pela ajuda que não esquecerei, no atendimento aos doentes e coleta do material.

Aos amigos Regina Celi e José Cezar de Almeida, pela admiração que nutrem pelo meu trabalho e pelo apoio irrestrito, que muito me confortam.

A todos aqueles, aos quais chamo de amigos, que em algum momento da elaboração deste trabalho, tiveram uma palavra de carinho e incentivo, pelo muito que me ajudaram. 
À DEUS, que nunca me faltou

À minha avó Didi (in memoriam), colo amigo de todas as horas,

À meus pais, Eronildes e Antonia, pela vida e por tudo que sou,

À meu marido César e minhas filhas Isadora e Clarissa, por me ensinarem o sentido das palavras amor, compreensão e alegria de viver,

À meus irmãos ,Carlos Alberto e Adalberto, amigos leais e incondicionais. 
DADOS DOS DOENTES PORTADORES DE RETOCOLITE ULCERATIVA GRAVE

\begin{tabular}{|c|c|c|c|c|c|c|}
\hline INICIAIS & RG-HC & SEXO & $\begin{array}{c}\text { COLETA PRÉ- } \\
\text { OP }\end{array}$ & $\begin{array}{l}\text { FECHAMENTO } \\
\text { ILEOSTOMIA }\end{array}$ & $\begin{array}{c}\text { BOLSA- } \\
1^{\circ} \mathrm{COLEETA}\end{array}$ & $\begin{array}{c}\text { BOLSA-2० } \\
\text { COLETA }\end{array}$ \\
\hline ARCMA & $3334795 \mathrm{~K}$ & $\mathrm{~F}$ & 05.01 .2001 & abr/02 & jun/02 & dez/02 \\
\hline MSM & $3043766 F$ & M & 29.03.2001 & abr/01 & jun/01 & dez/01 \\
\hline MJQ & 13023352 & M & 22.03 .2001 & mar/02 & mai/02 & nov/02 \\
\hline ACA & $13110908 \mathrm{G}$ & $\mathrm{F}$ & 26.04 .2001 & dez/01 & $\mathrm{mar} / 02$ & set/02 \\
\hline FAD & 1593959 & M & 02.07 .2001 & mar/02 & mai/02 & nov/02 \\
\hline RAS & $2446007 E$ & $\mathrm{~F}$ & 23.08.2001 & $\mathrm{mar} / 02$ & mai/02 & nov/02 \\
\hline APS & 1609120 & M & 30.08 .2001 & ago/02 & out/02 & mai/03 \\
\hline MGRJ & $3269724 \mathrm{H}$ & $\mathrm{F}$ & 13.09.2001 & dez/02 & fev/03 & jul/03 \\
\hline MNB & $3324011 G$ & $\mathrm{~F}$ & 18.10 .2001 & fev/03 & abr/03 & jul/03 \\
\hline JSR & 906 & $\mathrm{~F}$ & 21.03 .2002 & out/02 & dez/02 & jun/03 \\
\hline
\end{tabular}

